\title{
Video Article \\ Preparation of Gene Gun Bullets and Biolistic Transfection of Neurons in Slice Culture
}

\author{
Georgia Woods ${ }^{1}$, Karen Zito ${ }^{1}$ \\ ${ }^{1}$ Center for Neuroscience, University of California, Davis \\ URL: https://www.jove.com/video/675 \\ DOI: doi:10.3791/675
}

Keywords: neuroscience, issue 12, biolistics, cotransfection, hippocampal slice, organotypic, fluorescence microscopy, live imaging

Date Published: 2/13/2008

Citation: Woods, G., Zito, K. Preparation of Gene Gun Bullets and Biolistic Transfection of Neurons in Slice Culture. J. Vis. Exp. (12), e675, doi:10.3791/675 (2008).

\section{Abstract}

Biolistic transfection is a physical means of transfecting cells by bombarding tissue with high velocity DNA coated particles. We provide a detailed protocol for biolistic transfection of rat hippocampal slices, from the initial preparation of DNA coated bullets to the final shooting of the organotypic slice cultures using a gene gun. Gene gun transfection is an efficient and easy means of transfecting neurons and is especially useful for fluorescently labeling a small subset of cells in tissue slice. In this video, we first outline the steps required to coat gold particles with DNA. We next demonstrate how to line the inside of plastic tubing with the gold/DNA bullets, and how to cut this tubing to obtain the plastic cartridges for loading into the gene gun. Finally, we perform biolistic transfection of rat hippocampal slice cultures, demonstrating handling of the Bio-Rad Helios gene gun, and offering trouble shooting advice to obtain healthy and optimally transfected tissue slices.

\section{Video Link}

The video component of this article can be found at https://www.jove.com/video/675/

\section{Protocol}

\section{PROTOCOL FOR BIOLISTIC TRANSFECTION}

\section{Making bullets}

Bullets are good for up to 6 months, but may begin to decrease in transfection efficiency after $2-3$ months. Bullets should be stored at $4^{\circ} \mathrm{C}$ in the presence of dessicant pellets. Always let the scintillation vials, in which bullets are stored, warm to room temperature before opening the vial.

Before getting started have ready:

- $\quad$ Spermidine $(0.05 \mathrm{M})$

- $\mathrm{CaCl}_{2}(1 \mathrm{M})$

- $\mathrm{EtOH}(100 \%$-high grade-unopened bottle)

- Autoclaved $\mathrm{H}_{2} \mathrm{O}$

- DNA to be transfected

- Polyvinylpyrrolidone (PVP-20 mg/ml stock)

- $2 \times 15 \mathrm{ml}$ conical (2/bullet set)

- Tubing (cut into $1 X \sim 30$ inches/ bullet set)

- Scintillation vials $(1 /$ bullet set)

- Desiccation pellets

- $10 \mathrm{ml}$ syringe $\mathrm{w} /$ tubing on the end

\section{Prepare tubing:}

1. Dry $\sim 30$ inches of tubing (about 2 inches extending beyond right O-ring) in the tubing station $\mathrm{w} / \mathrm{N}_{2}$ gas $(0.4$ pressure) for a minimum of 20 $\min$.

\section{Precipitating DNA on gold beads:}

1. Prepare DNA to be transfected in $50 \mu \mathrm{mL}$ total volume in microcentrifuge tube (maximum $50 \mu \mathrm{g}$ total DNA)

2. Weigh out 6-8 $\mathrm{mg}$ of gold and transfer to an microcentrifuge tube

3. Add $100 \mu \mathrm{L}$ of $0.05 \mathrm{M}$ spermidine to gold and sonicate for $20 \mathrm{sec}$

4. Add the $50 \mu \mathrm{L}$ of DNA to the gold/spermidine

5. Vortex (around setting 5) w/cap open

6. Add drop wise $100 \mu \mathrm{L}$ of $1 \mathrm{M} \mathrm{CaCl}_{2}$ 
7. Sonicate briefly $(<5 \mathrm{sec})$

8. Allow to precipitate for $10 \mathrm{~min}$ at room temp

9. Sonicate briefly

Prepare PVP solution during sonication:

1. Make dilute PVP solution in $15 \mathrm{ml}$ conical, $3.5 \mathrm{~mL}$ dilute PVP for each set of bullets (add $7.5 \mu \mathrm{L} \mathrm{of} 20 \mathrm{mg} / \mathrm{ml} \mathrm{PVP} \mathrm{stock} \mathrm{to} 3.5 \mathrm{ml} 100 \%$ EtOH)

\section{Rinsing gold beads with EtOH:}

1. Spin down gold beads at full speed for $10 \mathrm{sec}$ in microcentrifuge

2. Discard supernatant, but keep a small amount of liquid on top of gold beads

3. Wash $3 \mathrm{X}$ with $1 \mathrm{ml} \mathrm{EtOH}$, sonicate briefly each time, if necessary

\section{Resuspend gold/DNA in PVP solution:}

1. Resuspend the gold pellet in $200 \mu \mathrm{L}$ of the $3.5 \mathrm{ml}$ dilute PVP/EtOH solution

2. Vortex the gold pellet to resuspend (briefly sonicate if necessary)

3. Transfer the $200 \mu \mathrm{L}$ of gold/PVP solution to a new $15 \mathrm{~mL}$ conical

4. Continue in this way, adding $200 \mu \mathrm{L}$ of PVP at a time until all the gold has been transferred to the $15 \mathrm{~mL}$ conical, and the final volume is 3.2 $\mathrm{mL}$

\section{Coating tubing:}

1. Turn off $\mathrm{N}_{2}$ at the tubing station and remove dried tubing

2. Attach dried tubing to the $10 \mathrm{ml}$ syringe

3. Vigorously shake the $15 \mathrm{~mL}$ conical filled with gold/PVP

4. Place the end of the tubing in gold/PVP solution and suck up slowly being careful to avoid bubbles

5. Leave $\sim 2$ inches dry from both ends of the tubing

6. With the tubing still attached to syringe and filled with the gold/PVP solution, carefully place the tubing back into station

7. Mark the ends of the tubing where the solution sits

8. Let the gold settle for 5 min with the syringe attached

9. Suck-up the solution very slowly by pulling the syringe so that the settled gold is left behind (make sure not to back-wash)

10. Disconnect syringe

11. Rotate $90^{\circ}$ and let sit 2 seconds

12. Rotate $180^{\circ}$ and let sit another 2 seconds

13. Rotate tube for $5 \mathrm{sec}$

14. Turn on the $\mathrm{N}_{2}$ so that the valve reads between $0.4-0.5$ and spin the gold-coated tubing while drying for $5 \mathrm{~min}$.

\section{Cutting tubing:}

1. Remove the tubing from the tubing prep-station and cut off the ends at the marks.

2. Put a labeled scintillation vial under the tubing chopper to catch cut cartridges

3. Place tubing in the tubing chopper and cut the tubing with clean razor

4. Place a desiccation pellets in scintillation vial

5. Store cartridges at $4^{\circ} \mathrm{C}$

\section{Shooting Tissue Slices}

When shooting cultured slices, it is important to employ a relatively sterile technique in order to avoid contamination. Remember, that when shooting two different constructs, both sets of bullets can be loaded into the same cartridge holder, but the barrel-liner and screen should be changed between constructs.

Before getting started have ready:

- DNA bullets (let scintillation vial warm to room temperature before opening)

- Tissue slices

- Helios Gene Gun

- Helium tank with gene gun hose attached

- Cartridge holder

- Barrel liner with plastic O-ring in place

- Diffuser (modified)

- Diffuser Screen

- Forceps

\section{Prepping the gene gun:}

1. Using forceps place the gold coated plastic cartridges into the cartridge holder.

2. Place the cartridge holder into the gene gun by first pushing back lock

3. Secure the cartridge holder with lock

4. Obtain a barrel liner with an O-ring and the diffuser screen securely in place 
5. Screw the barrel-liner into the gene gun

\section{Shooting cultured slices with the gene gun:}

1. Put on ear muffs

2. Plug the gene gun into hose connected Helium gas tank

3. Turn up pressure on tank to $180 \mathrm{PSI}$

4. Shoot a blank into the air in order to remove any dust or debris from the diffuser screen. To shoot the gun, first depress the safety interlock button until the gun beeps, then pull the trigger.

5. After shooting the blank, remove the slices from the incubator

6. Advance gun to first construct

7. Shoot with the diffuser screen about $0.5-1$ inch from the slice

8. Advance the cartridge between wells.

9. After shooting the last well, place the slices back into the incubator

10. Turn off gas and release pressure before detaching the gun from the Helium hose

11. Unscrew the barrel liner, and remove the cartridge and the used shells

\section{Cleaning cartridge holders and barrel liners:}

1. Place cartridges, barrel liners, and diffuser screens in a beaker with soapy water

2. Place beaker in bath sonicator and sonicate for $20 \mathrm{~min}$

3. Thoroughly rinse with water until all soap residues are removed

4. Soak in $70 \% \mathrm{EtOH}$ for an hour

5. Place on dry paper towel overnight to dry

6. Clean cartridges, barrel liners, and screens can then be reused in subsequent biolistic transfections

\section{Trouble shooting tips for Biolistic Transfection}

Biolistic transfection can sometimes result in suboptimal transfection conditions. It can lead to too few or too many cells transfected, too high or too low expression levels, or may cause tissue slices to become generally unhealthy. Often unhealthy slices result from the pressure blast. Here are some tips to obtain optimally transfected tissue slices.

If slices appear to be unhealthy (or if too many cells are transfected/ slice), try:

- increasing shooting distance

- decreasing pressure on gas tank

- decreasing the amount of gold

- cutting out the center of the Bio-Rad diffuser and replacing the center with a diffuser screen.

If too few cells are transfected, try:

- decreasing shooting distance

- increasing pressure on gas tank

- increasing the amount of gold

- increasing the number of tissue slices/ well

- make sure the O-ring in the barrel-liner is intact.

If you obtain slices with both too many AND too few cells transfected during the same shooting make sure:

- that you are holding the gun symmetrically above well

- that gold is evenly coating the inside of tubing. (If you are getting a line of gold, draw out the supernatant from the tubing at a faster rate once the gold has settled and rotate the gold longer before turning on the nitrogen. If, on the other hand, you are getting streaking of gold, this is likely due to too much moisture exposure during bullet making: make sure you are using an unopened bottle of EtOH, that the tubing is thoroughly dry before coating, and that you capping lids and preparing bullets in a timely manner).

If transfection efficiency seems optimal (\# cells transfected/ slice), but the expression level seems too high or too low:

- adjust the ratio DNA to gold. (e.g., if it is too low maintain the amount of gold but increase the amount of DNA.)

- adjust the amount of time between shooting and data collection

In the case of dual transfection, if you are getting too little expression of one of your constructs, adjust the ratio of the two constructs in the appropriate manner and make sure that both constructs are under the same promoter, so as to make sure that one promoter will not outcompete the other.

\section{Discussion}

Biolistic transfection is a physical means of transfecting cells via bombardment of living tissue with high velocity DNA coated gold particles. In particle mediated gene transfer, in general transfected cells result when the bullet comes to rest in the nucleus. While many different transfection methods exist, such as microinjection, lipofection, calcium-phosphate transfection, electroporation and viral transfection, biolistic transfection can offer a less labor intensive, and efficient alternative for transfecting cells that are not easily transfected using these other methods. In fact, 
it was first developed as a technique for gene transfer in plants since the presence of the cell wall made transfection difficult using preexisting methods ${ }^{1}$. Similarly, biolistics has gained popularity in the field of neurobiology since post-mitotic neurons are notoriously difficult to transfect ${ }^{2,3}$. In particular, it is widely recognized as the principle technique to be used in experiments aimed at assessing fine morphology of single neurons in intact brain slices. The methods described here provide a detailed and comprehensive explanation of how to perform biolistic transfection of cultured brain slices using a hand held gene-gun (the Helios Gene Gun system; Bio-Rad).

Biolistic transfection has become the preferred method for transfecting neurons in slice culture because it allows transfection of a sparse number of cells throughout the brain slice. In this way, individual neurons can be examined in isolation. Since this technique is particularly well suited for transfecting neurons in brain slice, it is often used in conjunction with 2-photon microscopy, since 2-photon excitation enables visualization of fluorescently labeled cells deep within light scattering tissue ${ }^{4}$. Indeed the high magnification images of single pyramidal neurons presented throughout this video were captured using a custom built 2-photon laser scanning microscope. In conclusion biolistic transfection is an efficient means of transfecting individual cells within the context of a high density of surrounding cells, and as such has proven extremely useful for fluorescently labeling individual neurons in neuronal slice culture.

\section{Acknowledgements}

We would like to thank Mark Lucanic and Hwai-Jong Cheng for help with acquiring the low magnification images of entire hippocampal slices presented in this video. We would also like to thank Sarah Parrish for aiding with the text accompanying the video.

\section{References}

1. Klein, TM., Fromm, M., Weissinger, A., Tomes, D., Schaaf, S., Sletten, M. and Sanford, JC. Transfer of foreign genes into intact maize cells with high-velocity microprojectiles. Proc. Natl. Acad. Sci. USA. 85, 4305-4309 (1988).

2. Wellmann, H., Kaltschmidt, B. and Kaltschmidt, C. Optimized protocol for biolistic transfection of brain slices and dissociated cultured neurons with a hand-held gene gun. J. Neurosci. Methods. 92, 55-64 (1999).

3. McAllister, AK. Biolistic transfection of neurons. Sci. STKE 51, 1-13 (2000).

4. Svoboda, K. and Yasuda, R. Principles of two-photon excitation microscopy and its applications to neuroscience. Neuron. 50, 823-839 (2006). 